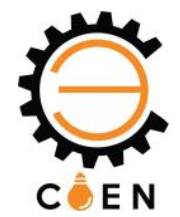

\title{
ANÁLISE DA PERCEPÇÃO À EXPOSIÇÃO AOS RISCOS: UM ESTUDO QUALITATIVO EM UMA EMPRESA DO SETOR DE GERAÇÃO E TRANSMISSÃO DE ENERGIA ELÉTRICA
}

\author{
Lara Jaques Leandro $^{(1)}$ (lah.jaquesl@ hotmail.com), Lucas Vale Canavez $^{(2)}$ (lvcanavez@ hotmail.com), \\ Ursula Scárlatt Aparecida Santos Silva ${ }^{(3)}$ (ursulascarlatt@ @otmail.com) \\ (1) Universidade Federal de São João del Rei (UFSJ) - Graduanda de Engenharia de Produção \\ (2) Universidade Federal de São João del Rei (UFSJ) - Graduando de Engenharia de Produção \\ (3) Universidade Federal de São João del Rei (UFSJ) - Graduanda de Engenharia de Produção
}

RESUMO: $O$ artigo trata-se de uma análise da percepção dos riscos, tanto ergonômicos quando de acidente, envolvendo eletricidade aos quais está exposto um trabalhador de uma estatal do setor de geração e transmissão de energia elétrica, cujo objetivo consiste em atestar a capacidade do mesmo em perceber tais riscos, compreendendo sua importância para a segurança e saúde no trabalho. Para tal, foram levantados fatores como idade, tempo de empresa e função desempenhada, avaliando como tais atributos afetam a percepção em cada um dos casos, obtidos a partir da aplicação de questionários semiestruturados no qual o empregado assinala o grau de concordância com afirmativas a respeito dos riscos supracitados, em uma escala predefinida. Foram aplicados, ainda, perguntas abertas possibilitando uma análise mais ampla e precisa das percepções individuais sobre tais riscos, bem como da sensação de segurança vivenciado por cada um dos empregados. Devido à necessidade de comprovação dos dados e visando assegurar respaldo cientifico às conclusões, fez-se uso do teste estatístico de análise de variância (ANOVA), alcançando resultados que apontam discrepâncias intensas na percepção média dos riscos inqueridos quando se compara as diferentes funções dentro da central elétrica, sendo mais suaves quando comparado à idade ou tempo de empresa. A partir desses resultados gerou-se conclusões a cerca das medidas a serem tomadas pela gestão da empresa.

PALAVRAS-CHAVE: Percepção de riscos, riscos ergonômicos, riscos de acidente, eletricidade.

\section{INTRODUÇÃO}

Os investimentos de capital estrangeiro no setor elétrico no Brasil tiveram início na primeira metade do século XX, experimentando o crescimento do número de hidrelétricas com a industrialização. Contudo, após a Segunda Guerra Mundial, em consequência do êxodo rural, a demanda por energia elétrica superou a oferta tornando o investimento na geração de eletricidade exponencial. A aplicação de capital neste setor esteve em falta, ocorrendo racionamento e aumento das taxas em diversos períodos, desde o século passado até os dias atuais, tornando seu uso imprescindível, sendo impensável o cotidiano sem sua disponibilidade.

Com cerca de 8,5 milhões de quilômetros quadrados, mais de 7 mil quilômetros de litoral e condições edafo-climáticas extremamente favoráveis, o Brasil possui um dos maiores e melhores potenciais energéticos do mundo, (Atlas de energia elétrica do Brasil, 2002, p. 7) destacando-se ainda por ser um dos maiores causadores de acidentes fatais. Silva (2015) evidenciam que o Brasil fora considerado recordista mundial de Acidentes de Trabalho (AT), dado que ocorre três mortes a cada duas horas e três AT não fatais a cada minuto.

A Organização Internacional do Trabalho (OIT, 2013), expôs suas estimativas de que dos 2,34 milhões de acidentes de trabalho mortais a cada ano, 321.000 se devem a acidentes, o que considera como déficit inaceitável do trabalho decente, gerando efeitos negativos não somente nos trabalhadores e suas 

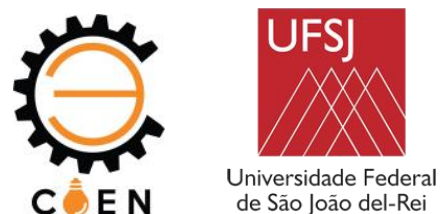

famílias, mas também perda de produtividade e sobrecarga dos sistemas de seguridade social, evidenciando que a problemática é civil.

Os números relacionados aos acidentes no trabalho impressionam negativamente, tornando imprescindível inovar na área de segurança e saúde no trabalho, o que compele as empresas a estender sua gestão para além do produto/ serviço até o trabalhador, atentando-se para sua segurança, saúde e integridade física, promovendo, assim, um ambiente mais seguro. (RODRIGUES et al. apud OLIVEIRA; VEIGA, 2013)

O estudo de Ergonomia mostra que a conscientização do trabalhador aos riscos ao qual está exposto é um dos resultados alcançado com sua aplicação satisfatória, isto porque "[...] visa, em primeiro lugar, a saúde, segurança e satisfação do trabalhador". (IIDA, 2005) Diante do estudo do sistema homem-máquinaambiente, no presente trabalho serão discutidos aspectos relacionados à "Percepção de Risco", que se constitui em um dos elos Segurança no Trabalho e que desempenha papel preponderante nas ações de prevenção de acidentes em uma empresa do setor de geração e transmissão de energia elétrica.

\section{REVISÃO DE LITERATURA}

\subsection{Ergonomia}

Tendo em vista que o foco deste artigo encontra-se no contexto industrial, o mesmo não minimiza sua importância no meio comercial, uma vez que a eletricidade está presente em todos os aspectos da vida de um indivíduo. Ante a esta problemática, torna-se incontestável a relevância deste estudo, devido á sua abrangência, tornando imperativa a elucidação de alguns conceitos pertinentes ao tema em questão.

Portanto, como refere-se a um estudo da percepção do proletário aos riscos inerentes ao trabalho e por conferir ao mesmo subsídios para sua adaptação aos meios de produção, proporcionando-lhe conforto e segurança a partir de métodos de prevenção de acidentes de trabalho, define-se ergonomia como sendo "[...]o estudo das interações das pessoas com a tecnologia, a organização e o ambiente, objetivando intervenções e projetos que visem melhorar, de forma integrada e não-dissociada, a segurança, o conforto, o bem-estar e a eficácia das atividades humanas". De acordo com o mesmo autor, a visão ergonômica é ampla e compreende tarefas que envolvem planejamento e projeto que ocorram anteriores ao trabalho realizado, e controle e avaliação, transcorridos durante e após a execução do mesmo. (IIDA, 2005, 2008)

Um trabalho de três anos na ABB de Cachoeirinha-RS, realizado pelo Núcleo de Design, Ergonomia \&Segurança (NDE) do LOPP/PPGEP/UFRGS, aumentou a produtividade em 17\% na montagem de dois modelos de medidores elétricos, reduzindo $70 \%$ do índice de DORT em função de melhorias ergonômicas efetuadas no produto fabricado, no posto e no sistema de trabalho como um todo. (Guimarães, 2002) Desse modo, em consonância com a Norma Regulamentadora NR-17 ${ }^{1}$, do Ministério do Trabalho e Emprego (2012), a ergonomia "[...] visa estabelecer parâmetros que permitam a adaptação das condições de trabalho às características psicofisiológicas dos trabalhadores, de modo a proporcionar um máximo de conforto, segurança e desempenho eficiente".

Em conformidade com Iida (2005), a análise dos postos de trabalho é o estudo de uma parte do sistema onde atua um trabalhador. O sistema preocupa-se com o funcionamento global de uma equipe de trabalho que usa uma ou mais máquinas, abrangendo aspectos generalistas, como a distribuição de tarefas entre o homem e a máquina, sua mecanização, entre outros. $O$ autor ainda declara que a abordagem ergonômica ao nível do posto de trabalho analisa a tarefa, a postura e os movimentos do trabalhador, bem como suas exigências físicas e cognitivas.

Contudo, preocupar-se com o trabalhador individualmente não é mais suficiente, visto que as organizações estão cada vez mais competitivas. Dessa forma, a participação dos colaboradores na organização da esfera laboral faz-se de extrema relevância para a incorporação das mudanças necessárias e

\footnotetext{
${ }^{1}$ A Norma Regulamentadora NR-17 intitula-se Ergonomia.
} 

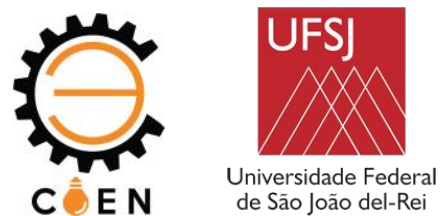

para a melhoria das condições dentro do sistema referenciado. A esse conceito dá-se o nome de macroergonomia.

Segundo Guimarães (2010), "a macroergonomia, diz respeito à ergonomia enfocada dentro de um contexto mais amplo, deixando de se restringir a questões pontuais para atuar, também, no processo organizacional. A visão macro atual focaliza o ser humano, o processo de trabalho e a organização, o ambiente e a máquina como um todo de um sistema mais amplo”. O autor considera ainda que a macroergonomia é a trilha para a implantação de um programa de ergonomia da empresa, com perspectiva de incorporação da segurança do trabalhador e da organização.

De acordo com Iida (2005), a macroergonomia é definida como "[...] desenvolvimento e aplicação da tecnologia da interface homem-máquina, em um nível macro, ou seja, em toda a organização". Hoje a empresa é considerada como sendo um sistema global, que deve ser estudado em sua totalidade, o que levou a consideração da ergonomia no projeto e na gerência das organizações. Por se tratar de um conceito mais atual de ergonomia, o estudo em questão foi realizado dentro do contexto de macroergonomia e envolve questões de otimização e segurança do trabalho, permitindo, assim, a participação dos empregados na mesma.

\subsection{Percepção aos riscos}

Em meio às diversas formas de energia utilizadas atualmente, a eletricidade é a mais empregada no âmbito industrial. No Brasil, o setor elétrico é um dos responsáveis pelo elevado número de acidentes fatais, uma vez que dispõe de sistemas complexos que apresentam condições laborais perigosas, resultando, frequentemente, em acidentes de trabalho. (SILVA, 2015) Dessa forma, a inovação na área de segurança e saúde no trabalho torna -se imprescindível, o que compele as empresas a estender sua gestão para além do produto/ serviço até o trabalhador, atentando-se para sua segurança, saúde e integridade física, promovendo, assim, um ambiente mais seguro. (RODRIGUES et al. apud OLIVEIRA; VEIGA, 2013)

Em conformidade com a norma ABNT NBR ISO 31000 (2009), define-se risco como sendo "efeito da incerteza nos objetivos", ou seja, é "[...] uma combinação das consequências de um evento (incluindo mudanças nas circunstâncias) e a probabilidade de ocorrência associada". Sendo assim, todas as instalações elétricas devem ser consideradas perigosas, uma vez que são fontes de inúmeros riscos, dentre os quais encontram-se os riscos elétricos.

De acordo com Junior et al. (2007), choque elétrico consiste na fluência de uma corrente elétrica através do corpo humano. Os sintomas podem incluir desde uma leve sensação de formigamento, a violentas contrações musculares, queimaduras, parada cardíaca e até mesmo a morte. Para o propósito deste estudo, assume-se que os danos aos tecidos causados por tais riscos, em sua grande maioria, estão sempre associados a queimaduras e aos danos às paredes celulares.

Segundo o Ministério do Trabalho e Emprego (2004), a Norma Regulamentadora NR-10², declara que em todas as intervenções feitas em instalações elétricas deve-se adotar medidas preventivas de controle do risco elétrico e de outros riscos adicionais, mediante técnicas de análise de risco, de forma a garantir segurança e saúde no trabalho. Afirma ainda que as medidas de controle adotadas devem integrar-se às demais iniciativas da empresa, no âmbito da preservação da segurança, da saúde e do ambiente do trabalho. No que se refere à manutenção e operação das instalações elétricas, as mesmas devem ser construídas, montadas, operadas, reformadas, ampliadas, reparadas e inspecionadas de forma a garantir segurança e saúde dos trabalhadores e dos demais usuários. Contudo, para possibilitar tal segurança é inevitável que ocorra treinamento adequado dos trabalhadores, o que lhes garantirão a competência necessária para compreender os riscos a que estão expostos.

\footnotetext{
${ }^{2}$ A Norma Regulamentadora NR-10 intitula-se Segurança em Instalações e Serviços em Eletricidade.
} 

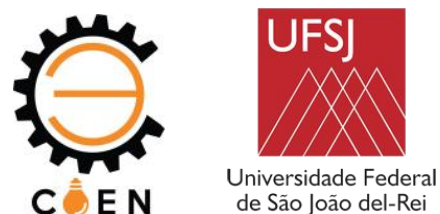

O tema Percepção de Riscos surgiu na década de 1960 em função da contrariedade na implantação da tecnologia nuclear, pela opinião pública, considerada pelos cientistas como sendo uma energia limpa. De acordo com Souto e Albuquerque (2015), é uma necessidade contemporânea compreender se o trabalhador tem condições de perceber os riscos do ambiente em que trabalha, visto que é de extrema importância para a empresa que quer aprimorar a sua Gestão de Segurança e Saúde do Trabalhador. Os autores declaram ainda que investigar e analisar a percepção de riscos do trabalhador como uma componente das causas dos acidentes do trabalho, possibilita a adoção de medidas administrativas específicas para esta causa, com repercussão na redução da ocorrência dos acidentes. Segundo Silva e França (2011), o mapeamento da percepção de riscos dos trabalhadores permite, de certa maneira, avaliar a importância que estes dão ao processo de gestão de Segurança e Saúde do Trabalhador na empresa. Muitas vezes o proletário comete comportamentos inseguros por não conhecer de fato os riscos aos quais está exposto em seu ambiente de trabalho.

Diante deste contexto, torna-se claro a importância em se estudar a percepção do risco a que estão expostos os trabalhadores, em particular, os funcionários de uma empresa do setor de geração e transmissão de energia elétrica, analisando seu comportamento e sua capacidade de observação ás periculosidades ao seu redor, compreendendo sua segurança no ambiente de trabalho.

\section{MATERIAIS E MÉTODOS}

\subsection{O Objeto da Pesquisa}

Esse artigo tem como propósito analisar a percepção à exposição do trabalhador aos riscos concernentes à eletricidade em uma estatal do setor de geração e transmissão de energia. Sendo assim, o presente estudo aborda o comportamento do mesmo, analisando tanto sua capacidade de observação perante as periculosidades ao seu redor, quanto sua compreensão de segurança e saúde no ambiente de trabalho. Para tal, os autores utilizaram como objeto de pesquisa funcionários de uma empresa do setor de geração e transmissão de energia elétrica, no qual os dados para a referida análise foram coletados nas áreas de operação, manutenção eletromecânica e manutenção eletroeletrônica da dita empresa, por meio de questionário fechado, com alternativas escalonadas, encaminhados via correio eletrônico.

O trabalho desempenhado pelos técnicos de manutenção eletromecânica intercorrem em três frentes distintas, a saber: manutenção de linhas de transmissão, manutenção de equipamentos de subestação e manutenção de equipamentos de usina. Os profissionais de linha de transmissão realizam atividades em linhas desligadas ou energizadas, dentre as quais encontram-se as atividades de substituição de isoladores, de sinalizadores e de espaçadores; montagem de torres e lançamento de cabos de transmissão de energia elétrica, e montagem de para-raios e lançamento de cabos dos para-raios, executando também, serviço de inspeção e roço da vegetação ao longo da linha de transmissão. Dentre as atividades dos técnicos de manutenção de equipamentos de subestação estão às intervenções corretivas e preventivas em transformadores, reatores, bancos de capacitores, chaves seccionadoras e disjuntores, incluindo diagnósticos de falha, limpeza, substituição de peças defeituosas, ensaios não destrutivos, coleta de óleo para análise, dentre outros, efetuando, também, inspeções nos equipamentos sob sua responsabilidade. Já os profissionais que atuam na manutenção de usinas trabalham com manutenção corretiva e preventiva nos diversos equipamentos de usina como geradores, comportas, entre outros, executando a limpeza, a substituição de peças defeituosas e os ensaios não destrutivos, bem como inspecionam os equipamentos associados à sua função.

Os técnicos de manutenção eletroeletrônica são responsáveis tanto pela manutenção de equipamentos de proteção e controle quanto pela manutenção de equipamentos de telecomunicação. As atividades desempenhadas na manutenção de equipamentos de proteção e controle resumem-se em suporte corretivo e preventivo de componentes eletrônicos em painéis de proteção e controle, de unidades de 
aquisição e controle (UAC) e de controladores lógicos programáveis (CLP), sendo também, responsáveis pelo processamento de diagnósticos de falhas, substituindo componentes defeituosos assim como realizando ensaios não destrutivos e inspeções nos equipamentos. Os técnicos de manutenção de equipamentos de telecomunicação trabalham na manutenção preventiva e corretiva em emissores de micro-ondas, equipamentos de estações transmissoras de ondas de rádio, equipamentos de estações repetidoras de microondas, em centrais telefônicas e em centrais de rede ADSL, realizando diagnósticos de falha, substituições de componentes defeituosos e inspeções nos equipamentos.

Os operadores de usina e subestação possuem rotina parecida com as já citadas, em que consiste na realização de inspeções periódicas dos equipamentos tanto de usina quanto de subestação e inspeções termográficas, sendo também os encarregados das manobras nos equipamentos de usina e subestação.

\subsection{A Empresa}

A empresa onde fez-se os levantamento dos dados traduz-se em uma estatal do setor de geração e transmissão de energia elétrica, no qual é responsável pela produção de aproximadamente $10 \%$ da energia gerada no país. O complexo possui, em sua totalidade, 20 usinas hidrelétricas, decompondo-se em seis próprias, seis sob administração especial (Lei $n^{\circ} 12.783 / 2013$ ), duas em parceria com iniciativa privada, nove em Sociedades de Propósito Específico (SPEs), duas termelétricas e três parques eólicos. Esse conjunto abastece o mercado brasileiro com 17,3 mil MW de potência instalada, dos quais 11,6 mil MW é de propriedade da empresa estudada. A transmissão da energia ocorre a partir de 24 mil quilômetros de linhas, em que $3.528 \mathrm{~km}$ encontram-se sob a forma de participação em SPEs, possuindo ainda 71 subestações, dos quais 51 são próprias, 19 em SPEs e uma em Parceria Pública Privada (PPP), com capacidade de transformação total de 109.676 MVA.

A empresa apresenta uma estrutura organizacional com cinco diretorias diretamente subordinadas à presidência, dentre as quais se encontra a Diretoria de Operação e Manutenção, que por sua vez dispõe de sete gerências de produção, classificadas por região geográfica. Dentre essas gerencias encontra-se a Gerência de Produção Minas, responsável pela administração dos empreendimentos no estado de Minas Gerais, sendo esta a fornecedora dos dados desta pesquisa. 


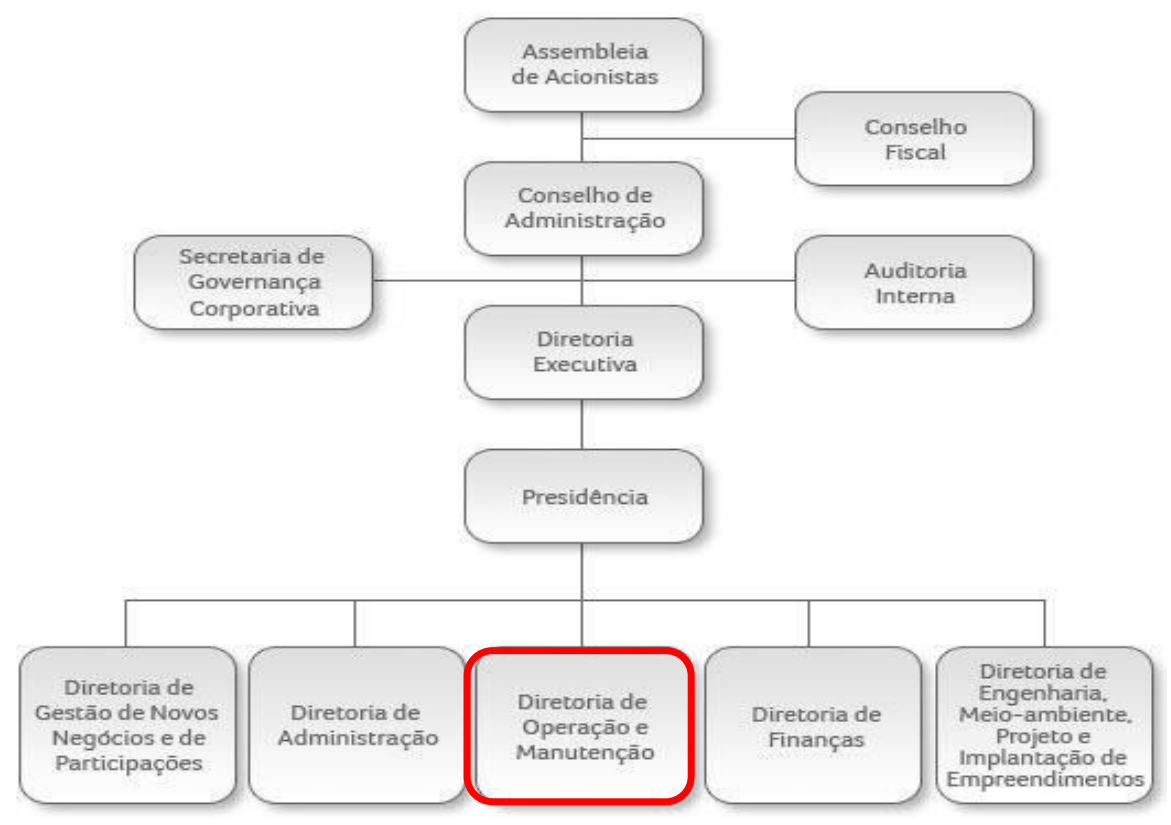

Figura 1. Demonstrativo da estrutura organizacional da empresa

A Gerência de Produção Minas é composta por três subestações e três usinas hidrelétricas, das quais duas subestações estão administrativamente subordinadas a uma das usinas. As demais possuem estrutura própria de gestão, denominadas divisão, responsáveis, em termos de operação e manutenção, apenas pelos operadores, sendo que os profissionais de manutenção ainda respondem a outras duas divisões específicas de manutenção, cuja estrutura administrativa encontra-se centralizada em uma das usinas e seus profissionais pulverizados nos empreendimentos da Gerência de Produção Minas. Essas divisões específicas de manutenção são a Divisão de Manutenção Eletromecânica e a Divisão de Manutenção Eletroeletrônica.

\section{APLICAÇÃO DO MÉTODO}

Diante da grande quantidade de riscos a que um trabalhador se expõe dentro de uma estatal de geração e transmissão de energia, torna-se inevitável a redução dos tipos de riscos para ergonômicos e de acidentes, visto que os autores não possuíam tempo, tão pouco o acesso necessário para uma análise mais ampla e completa do tema em questão.

Com o intuito de comprovar a capacidade de percepção dos operários a esses riscos específicos, avaliou-se as seguintes variáveis, a saber: idade, gênero, função desempenhada e tempo trabalhado na empresa. Para tal, realizou-se pesquisa por meio de aplicação de questionários de autopreenchimento informatizados, através da plataforma Google Forms. (MATHIAS; SAKAI. 2013) Esse aplicativo encontrase no Google Docs, um serviço do Google que permite a edição colaborativa de documentos, sendo escolhida devido a sua apresentação, facilidade de uso, da forma organizada e simples com que são apresentadas as respostas e por atender os requisitos de confidencialidade e anonimato indispensáveis à realização desta pesquisa, além da frequente utilização em artigos científicos conforme averiguado nas plataformas de busca Google Acadêmico e Scielo.

No cabeçalho do questionário solicita-se informações pessoais do empregado como idade, gênero, tempo de atividade na empresa e tipo de trabalho executado, com o propósito de estratificar e comparar dados pertinentes à pesquisa. Quanto à sua forma, o questionário foi segmentado em duas partes, uma 

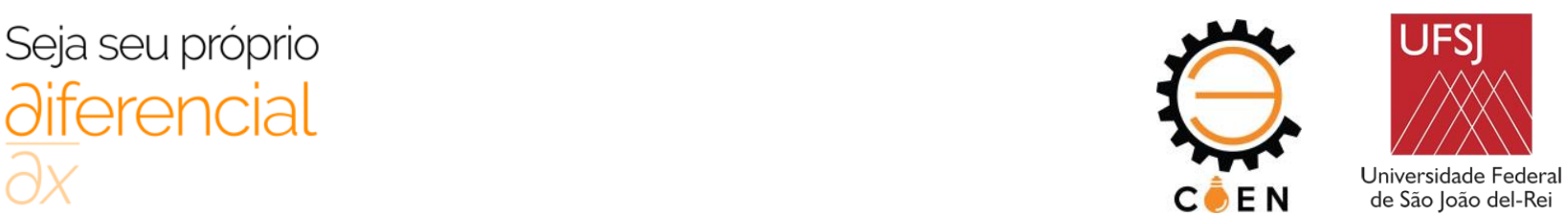

qualitativa com perguntas subjetivas e uma parte semi-quantitativa (GUIMARÃES, 2010) cujas afirmativas seguem o tipo de escala likert, que segundo Vieira e Dalmoro (2008), consiste em uma escala de pontos, contendo cinco categorias de respostas que vão de "discordo totalmente" a "concordo totalmente". Contudo, Guimarães recomenda o uso de escala com ancoras na extremidade e sem ancora central, uma vez que constatou-se que ao se utilizar a forma com ponto ou ancora central existe uma tendência do entrevistado se neutralizar, o que pode vir a comprometer a credibilidade da pesquisa.

Por se tratar de uma análise macroergonômica (GUIMARÃES, 2010) envolvendo ergonomia e riscos próprios do setor elétrico, os questionários foram semiestruturados e divididos em três segmentos. São eles: a percepção de riscos ergonômicos, a autoavaliação de danos devido ao risco ergonômico e a percepção de riscos envolvendo eletricidade, tendo os dois primeiros segmentos sido embasadas na norma regulamentadora NR-17 e no artigo ESTRESSE OCUPACIONAL E SUAS PRINCIPAIS CAUSAS E CONSEQUÊNCIAS, de Juliana F. C. Silva. No que tange a estruturação de cada uma das partes dos dois segmentos iniciais, a primeira seção dispõe de cinco afirmativas sobre a percepção de risco ergonômico, no qual o interpelado assinala em uma escala de zero a cinco sua concordância com tais afirmativas. Na segunda seção, são apresentadas seis frases no qual o entrevistado também assinala seu grau de concordância na mesma escala da seção anterior. Finalizando a temática ergonomia, na terceira seção é apresentada uma afirmativa em que o entrevistado avalia o quanto é ergonomicamente seguro seu ambiente de trabalho.

O terceiro segmento do questionário, sobre percepção de riscos envolvendo eletricidade, dispõe de três afirmativas sobre risco de acidente com eletricidade para que o entrevistado avalie o quanto concorda com cada uma, na mesma escala supracitada; mais duas questões subjetivas, em que permite ao interpelado sugerir inovações que visem sua segurança e apontar riscos a que está exposto não contemplado pela norma. Essas afirmativas foram baseadas na norma regulamentadora NR10 e no artigo PERCEPÇÃO DE RISCO: UMA ABORDAGEM INOVADORA E PARTICIPATIVA NO SETOR ELÉTRICO, dos autores Clodovaldo Nogueira Souto e Gerson Luiz Apoliano Albuquerque.

Os resultados da referida pesquisa foram plotados no Minitab, software estatístico cuja versão introdutória se deu na década de 70 com a intenção de facilitar o aprendizado de estatística, e que disponibiliza as "[...] ferramentas necessárias para analisar com eficácia os [...] dados [...] através da análise correta [...]”, fornecendo exatidão aos resultados além de auxiliar na resolução significativa dos problemas em questão. Das diversas ferramentas fornecidas pelo software supracitado, os autores utilizaram a análise de variância (ANOVA) em que compararam a variável de resposta, nos diferentes níveis de fatores, avaliando sua importância ${ }^{3}$.

\section{RESULTADOS}

O formulário, de preenchimento voluntário, foi enviado via correio eletrônico para 350 funcionários da empresa, ficando disponível em média sete dias, obtendo apenas 60 respostas. Das variáveis consideradas, o fator gênero não afetou a percepção dos trabalhadores aos riscos à eletricidade, sendo esta desconsiderada na análise dos resultados. As demais variáveis influenciaram diretamente o estudo da percepção aos riscos, ergonômicos e de acidentes, a que se expõe os trabalhadores da estatal elétrica referenciada. A Figura 2 mostra a distribuição, por idade, dos funcionários na amostra em que se constata que a maioria dos funcionários desta empresa possuem idades entre 30 e 50 anos.

\footnotetext{
${ }^{3}$ MINITAB. Disponível em: <https://www.minitab.com/pt-br/products/minitab/>. Acesso em: 10 jul. 2017.
} 


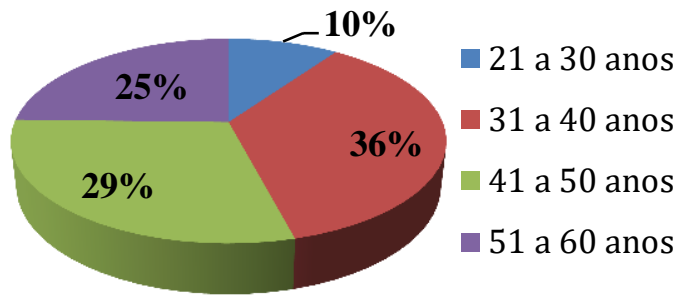

Figura 2. Distribuição quanto à idade dos trabalhadores da centra de geração e transmissão de energia

Como já mencionada, a empresa supracitada possui duas divisões, operacional e de manutenção, no qual as principais atividades desempenhadas são de operação e manutenção (eletromecânica e eletroeletrônica). A partir dos dados recolhidos (fig. 3), verificou-se que dos 60 entrevistados 44 desempenham tarefas no setor de manutenção, 15 funcionários são responsáveis pela parte operacional e apenas um executa outro tipo de atividade.

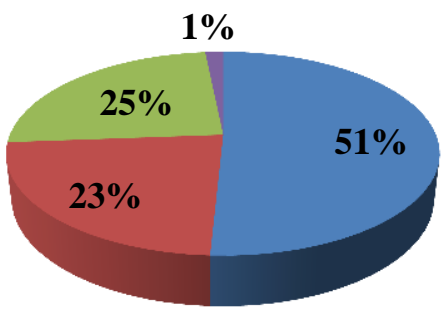

$$
\begin{aligned}
& \text { Manutenão Eletromecânica } \\
& \text { Manutenão Eletroeletrônica } \\
& \text { Operador } \\
& \text { - Outras }
\end{aligned}
$$

Figura 3. Distribuição quantos à atividade desempenhada na central elétrica

A Figura 4 expõe a relação de funcionário por tempo de serviço, sendo esta a terceira variável analisada. Como observado no gráfico de pizza, cerca de um quarto dos entrevistados prestam serviço por tempo inferior a 10 anos, metade deles a mais de 10 anos e os demais superam os 20 anos de empresa.

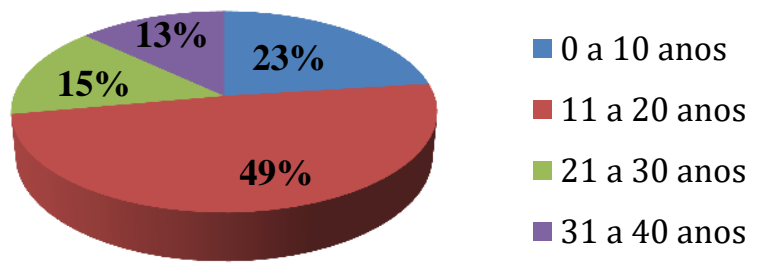

Figura 4. Relação de funcionário por tempo de serviço

Como consequência dos questionamentos propostos aos entrevistados, obteve-se os percentuais evidenciados nos quadros que se seguem. Como declarado, o questionário, escalonado entre 0 a 5 , subdividiu-se em três frentes: a percepção de riscos ergonômicos, a autoavaliação de danos devido ao risco ergonômico e a percepção de riscos envolvendo eletricidade. Na Tabela 1, referente à percepção de riscos ergonômicos, pôde-se notar uma tendência a escolha do ponto 4, com exceção da terceira e quarta pergunta em que teve-se maioria voltada para o ponto 3 , significando que os entrevistados concordam mais do que discordam. 
Tabela 1. Resultados dos questionamentos da seção inicial aplicado aos trabalhadores da central elétrica

\begin{tabular}{|c|c|c|c|c|c|c|}
\hline \multirow{2}{*}{$\begin{array}{c}\text { SEÇÃOO I } \\
\text { PERCEPÇÃO AS RISCOS ERGONOMICOS }\end{array}$} & \multicolumn{5}{|c|}{ ESCALA \% } & \multirow[b]{2}{*}{5} \\
\hline & $\mathbf{0}$ & 1 & 2 & 3 & 4 & \\
\hline 1) Exigência de esforço físico nas atividades desempenhadas & 1,6 & 6,6 & 6,6 & 23 & 31,1 & 31,1 \\
\hline $\begin{array}{l}\text { 2) Exigência de posturas inadequadas nas atividades } \\
\text { desempenhadas }\end{array}$ & 3,3 & 6,6 & 16,4 & 6,6 & 42,6 & 24,6 \\
\hline $\begin{array}{l}\text { 3) Existência de atividades com controle rígido de produção e/ ou } \\
\text { ritmos excessivos }\end{array}$ & 9,8 & 18 & 14,8 & 31,1 & 16,4 & 9,8 \\
\hline 4) Atividades repetitivas e/ ou monótonas & 4,9 & 18 & 21,3 & 27,9 & 16,4 & 11,5 \\
\hline $\begin{array}{l}\text { 5) Iluminação adequada nos postos de trabalho (iluminação } \\
\text { artificial) }\end{array}$ & 1,6 & 1,6 & 18 & 18 & 39,3 & 21,3 \\
\hline
\end{tabular}

Fonte: Autoria própria

A segunda rodada de perguntas, destina-se a analisar a capacidade de autoavaliação do entrevistado quantos aos danos derivados dos riscos ergonômicos (tab. 2). Observou-se nesta etapa uma propensão ao lado direito da escala, evidenciando o incomodo dos trabalhadores quantos aos danos provocados por tais riscos. No entanto, no que tange a mudança de regime de turnos e ao desconforto ocular proveniente da iluminação inadequada, verificou-se total ausência de percepção por parte desses entrevistados, concluindo que, ao que se refere aos pontos citados, não há nenhum desconforto.

Tabela 2. Resultados dos questionamentos da segunda seção aplicada aos trabalhadores da central elétrica

\begin{tabular}{|c|c|c|c|c|c|c|}
\hline \multirow{2}{*}{$\begin{array}{c}\text { SEÇÃO II } \\
\text { AUTOAVALIAÇÃO DOS DANOS DERIVADOS DOS } \\
\text { RISCOS ERGONÔMICOS }\end{array}$} & \multicolumn{6}{|c|}{ ESCALA \% } \\
\hline & $\mathbf{0}$ & 1 & 2 & 3 & 4 & 5 \\
\hline $\begin{array}{l}\text { 6) Sensação de dores e/ ou desconforto durante a execução de } \\
\text { atividades que envolva esforço físico }\end{array}$ & 1,6 & 13,1 & 14,8 & 31,1 & 37,7 & 1,6 \\
\hline $\begin{array}{l}\text { 7) Sensação de dores e/ ou desconforto durante a execução de } \\
\text { atividades que necessitam de postura inadequada }\end{array}$ & 0 & 4,9 & 21,3 & 29,5 & 36,1 & 8,2 \\
\hline $\begin{array}{l}\text { 8) Sensação de desconforto durante/ após a execução de } \\
\text { atividades com controle rígido de produção e/ ou ritmos } \\
\text { excessivos }\end{array}$ & 11,5 & 18 & 13,1 & 24,6 & 27,9 & 4,9 \\
\hline $\begin{array}{l}\text { 9) Sensação de fadiga, estresse e/ ou irritabilidade em regime de } \\
\text { turnos }\end{array}$ & 26,3 & 21,1 & 10,5 & 10,5 & 13,2 & 18,4 \\
\hline $\begin{array}{l}\text { 10) Sensação de fadiga, estresse e/ ou irritabilidade na execução } \\
\text { de atividades repetitivas e/ ou monótonas }\end{array}$ & 13,3 & 17,8 & 15,6 & 37,8 & 13,3 & 2,2 \\
\hline $\begin{array}{l}\text { 11) Sensação de desconforto ocular e /ou dores de cabeça } \\
\text { decorrentes da Iluminação adequada }\end{array}$ & 28,8 & 16,9 & 10,2 & 23,7 & 16,9 & 3,4 \\
\hline $\begin{array}{l}\text { 12) SEGURIDADE ERGONÔMICA DO AMBIENTE DE } \\
\text { TRABALHO }\end{array}$ & 9,8 & 3,3 & 21,3 & 32,8 & 24,6 & 8,2 \\
\hline
\end{tabular}

Fonte: Autoria própria

O ultimo segmento refere-se à percepção aos riscos que envolvem eletricidade, no qual percebe-se, através da Tabela 3, uma disposição de respostas concordantes. Foi detectado ainda que 55\% dos entrevistados acreditam na possibilidade de tornar o ambiente mais seguro, partindo de mudanças na forma 
da execução do trabalho e cerca de $70 \%$ dos mesmos afirmam que é incapaz eliminar alguns riscos mesmo com o cumprimento da norma NR-10.

Tabela 3. Resultados dos questionamentos da terceira seção aplicada aos trabalhadores da central elétrica

\begin{tabular}{|c|c|c|c|c|c|c|}
\hline SEÇÃO III & \multicolumn{6}{|c|}{ ESCALA \% } \\
\hline EXPOXIÇÃO AOS RISCOS INERENTES À ELET & $\mathbf{0}$ & 1 & 2 & 3 & 4 & 5 \\
\hline 13) Classificação quanto ao perigo do risco elétrico & 0 & 4,9 & 6,6 & 13,1 & 29,5 & 45,9 \\
\hline $\begin{array}{l}\text { 14) Sensação de segurança após cumprimento dos requisitos da } \\
\text { NR-10 }\end{array}$ & 1,6 & 1,6 & 1,6 & 13,1 & 50,8 & 31,1 \\
\hline $\begin{array}{l}\text { 15) O quanto o trabalhador está sujeito a sofrer acidente com } \\
\text { eletricidade }\end{array}$ & 0 & 16,4 & 19,7 & 14,8 & 29,5 & 19,7 \\
\hline
\end{tabular}

Fonte: Autoria própria

A partir dos dados obtidos pôde-se realizar as análises pertinentes ao estudo e gerar conclusões a cerca do tema em questão. Contudo, para um resultado mais exato necessitar-se-ia de um número maior de respostas, que representassem, de forma mais precisa, a realidade de empresa, visto que apenas 60 funcionários se disponibilizaram a responder o referido questionário.

\section{ANÁLISE E DISCUSSÃO DOS RESULTADOS}

A utilização da estatística em análise de dados pelas organizações tem sido de grande importância, pois auxilia os gestores na tomada de decisão (KMITA; GUIMARÃES, 2006). De acordo com a Escola Nacional de Ciências Estatísticas (ENCE), define-se estatística como sendo "[...] um conjunto de técnicas e métodos de pesquisa e análise de dados que entre outros tópicos envolve o planejamento do experimento a ser realizado, a coleta qualificada dos dados, a inferência, o processamento, a análise e a disseminação das informações".

Devido à necessidade de comprovação dos dados e para assegurar respaldo cientifico às conclusões, optou-se pela utilização do teste estatístico de análise de variância (ANOVA), que determinará a existência de variações significativas entre os fatores que influenciam a percepção do trabalhador aos riscos do trabalho e, caso exista, quais diferem significativamente entre si. Para tal, testa-se o significado estatístico de cada um dos fatores considerados "influentes", denominando-os de p-valor. Considerando um intervalo de confiança de 95\%, para atestar que os referidos fatores possuem efeito estatístico significativo, seu p-valor obrigatoriamente precisa ser menor que 0,05 .

Os fatores idade, tempo de empresa e função foram delimitados, sendo a primeira variável formada por quatro grupos com nove anos cada, partindo de 21 até 60 anos de idade, a segunda composta por grupos de 0 a 10 , de 11 a 20 , de 21 a 30 e de 31 a 40 anos trabalhados e a ultima variável subdivididas em três cargos - operadores (OP), eletroeletrônicos (EE) e eletromecânicos (EM) - sendo comprovados por meio de questionamento aos empregados da estatal elétrica. No entanto, apenas algumas questões serviram ao propósito pretendido, visto que o p-valor atendia a condição estipulada. A tabela 4 apresenta a análise de variância dos fatores Idade, Função e Tempo de Empresa.

Tabela 4. Análise de Variância (ANOVA)

\begin{tabular}{cccccccc}
\hline Variável & Questão & Fonte & GL & SQ (Aj.) & QM (Aj.) & Valor F & Valor-P \\
\hline \multirow{3}{*}{ Idade } & & Fator & 3 & 14,15 & 4,715 & 2,85 & 0,045 \\
& $\mathbf{3}$ & Erro & 60 & 99,21 & 1,654 & & \\
& & Total & 63 & 113,36 & & & \\
\hline
\end{tabular}




\begin{tabular}{|c|c|c|c|c|c|c|c|}
\hline \multirow{3}{*}{ Idade } & \multirow{3}{*}{7} & Fator & 3 & 8,665 & 2,888 & 2,87 & 0,044 \\
\hline & & Erro & 56 & 56,318 & 1,006 & & \\
\hline & & Total & 59 & 64,983 & & & \\
\hline \multirow{3}{*}{ Idade } & \multirow{3}{*}{8} & Fator & 3 & 21,19 & 7,062 & 3,54 & 0,02 \\
\hline & & Erro & 56 & 111,8 & 1,996 & & \\
\hline & & Total & 59 & 132,98 & & & \\
\hline \multirow{3}{*}{ Função } & \multirow{3}{*}{1} & Fator & 2 & 31,46 & 15,732 & 13,91 & 0 \\
\hline & & Erro & 57 & 64,47 & 1,131 & & \\
\hline & & Total & 59 & 95,93 & & & \\
\hline \multirow{3}{*}{ Função } & \multirow{3}{*}{2} & Fator & 2 & 39,52 & 19,758 & 15,34 & 0 \\
\hline & & Erro & 57 & 73,42 & 1,288 & & \\
\hline & & Total & 59 & 112,93 & & & \\
\hline \multirow{3}{*}{ Função } & \multirow{3}{*}{3} & Fator & 2 & 22,06 & 11,029 & 6 & 0,004 \\
\hline & & Erro & 57 & 104,79 & 1,838 & & \\
\hline & & Total & 59 & 126,85 & & & \\
\hline \multirow{3}{*}{ Função } & \multirow{3}{*}{6} & Fator & 2 & 15,58 & 7,789 & 6,96 & 0,002 \\
\hline & & Erro & 57 & 63,82 & 1,12 & & \\
\hline & & Total & 59 & 79,4 & & & \\
\hline \multirow{3}{*}{ Função } & \multirow{3}{*}{7} & Fator & 2 & 6,612 & 3,306 & 3,26 & 0,044 \\
\hline & & Erro & 77 & 78,187 & 1,015 & & \\
\hline & & Total & 79 & 84,8 & & & \\
\hline \multirow{3}{*}{ Função } & \multirow{3}{*}{8} & Fator & 2 & 17,48 & 8,742 & 4,31 & 0,018 \\
\hline & & Erro & 57 & 115,5 & 2,026 & & \\
\hline & & Total & 59 & 132,98 & & & \\
\hline \multirow{3}{*}{ Tempo } & \multirow{3}{*}{1} & Fator & 3 & 21,57 & 7,189 & 5,22 & 0,003 \\
\hline & & Erro & 71 & 97,71 & 1,376 & & \\
\hline & & Total & 74 & 119,28 & & & \\
\hline \multirow{3}{*}{ Tempo } & \multirow{3}{*}{2} & Fator & 3 & 18,75 & 6,252 & 3,61 & 0,019 \\
\hline & & Erro & 54 & 93,59 & 1,733 & & \\
\hline & & Total & 57 & 112,34 & & & \\
\hline \multirow{3}{*}{ Tempo } & \multirow{3}{*}{6} & Fator & 3 & 15,02 & 5,007 & 4,2 & 0,01 \\
\hline & & Erro & 54 & 64,36 & 1,192 & & \\
\hline & & Total & 57 & 79,38 & & & \\
\hline \multirow{3}{*}{ Tempo } & \multirow{3}{*}{7} & Fator & 3 & 8,329 & 2,7764 & 2,9 & 0,043 \\
\hline & & Erro & 54 & 51,757 & 0,9585 & & \\
\hline & & Total & 57 & 60,086 & & & \\
\hline
\end{tabular}

Fonte: Autoria própria

Por meio da ANOVA pôde-se delimitar a análise dos dados, direcionando o foco dos autores para os fatores que sofreram efeito estatístico significativo. Tal análise gerou um gráfico de intervalos, como exemplificado no Figura 5, cuja variável considerada foi a idade de cada funcionário, avaliando, neste caso em específico, a 
existência de atividades com controle rígido de produção e/ ou ritmos excessivos, em que nota-se equivalência nas médias dos grupos intermediários (31 a 40 anos e 41 a 50 anos). Após plotagem, fez-se uma análise individual de cada grupo, verificando quais apresentavam p-valor inferior a 5\%, fato observado apenas nos grupos intermediários (fig. 6$)^{4}$.

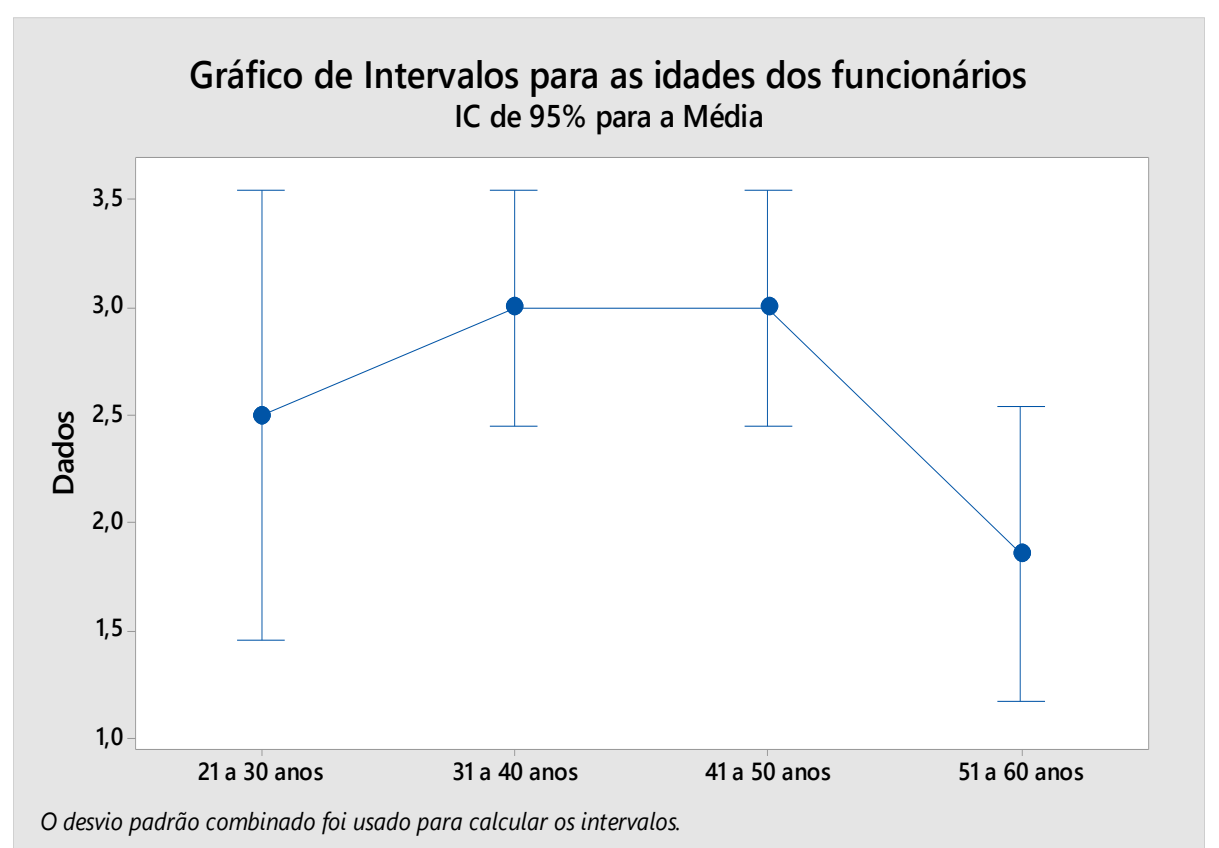

Figura 5. Intervalo para as idades dos funcionários para a questão "existência de atividades com controle rígido de produção e/ ou ritmos excessivos"

\footnotetext{
${ }^{4}$ A análise de todas as questões listadas na Tabela 4 seguiu o mesmo princípio descrito, preferindo os autores não apresentar seus gráficos, apenas suas conclusões, visto que por se tratar de muitos tópicos, a quantidade de gráfico poderia tornar o artigo extenso, além de não serem de fácil interpretação, necessitando que o leitor tenha proximidade a acerca de sua metodologia.
} 

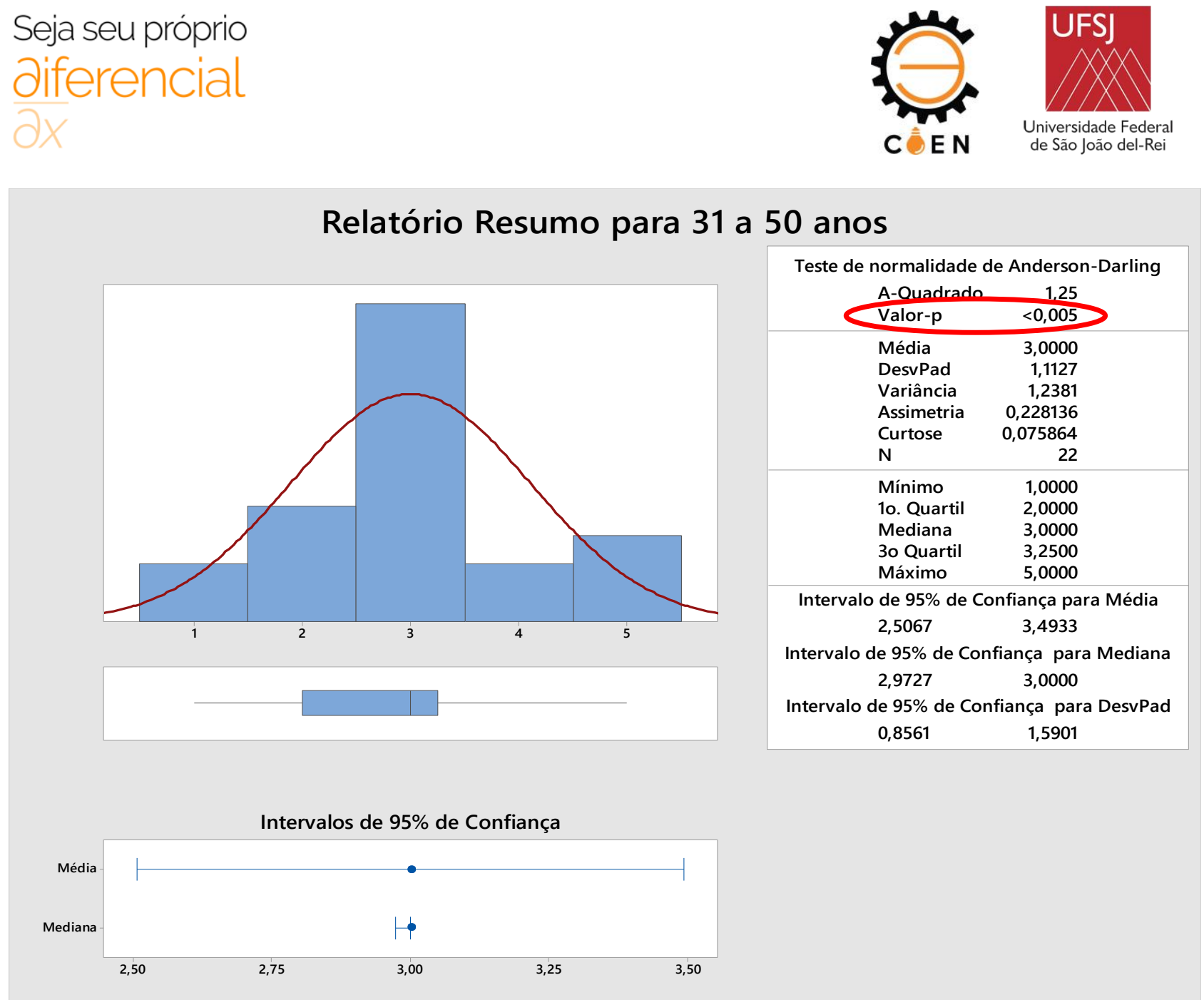

Figura 6. Relatório para o intervalo de idades [31-40] e [41 a 50] referente à questão "existência de atividades com controle rígido de produção e/ ou ritmos excessivos"

Isso posto, ao analisar a Tabela 4, nota-se que a idade afeta progressivamente a percepção dos trabalhadores quanto à realização de atividades com rígido controle de produção e/ ou ritmos excessivos, o que acarreta dores e/ ou desconforto, sensação esta observada também em atividades que necessitam de postura inadequada. No que tange às funções exercidas pelos trabalhadores, observou-se que os mesmos têm ciência dos riscos ergonômicos atribuídos às atividades desempenhadas e que sentem dores e/ ou desconforto ao realiza-las. Já em relação a variável tempo trabalhado na empresa, verificou-se que os funcionários com até 20 anos de empresa sentem mais dores e/ ou desconforto em atividades que exigem maior esforço físico e posturas inadequadas.

Uma análise mais acurada dos dados mostrou que as atividades que demandam rígido controle de produção e/ ou ritmos excessivos são destinadas aos trabalhadores com idade entre 30 e 50 anos, sendo este os mais afetados, visto que a maioria das queixas de desconforto na execução da tarefa se encontra entre o grupo de trabalhadores com idade entre 30 e 40 anos. Ademais, os funcionários cuja idade encontra-se entre 20 e 50 anos relataram sentir dores e/ ou desconforto durante a execução das atividades que necessitam postura inadequada.

Através da verificação dos resultados gerados a partir do parâmetro função/ cargo, constatou-se que os operadores das três funções analisadas desempenham atividades que exigem esforço físico. Entretanto, apenas os trabalhadores das áreas de manutenção sentem dores e/ ou desconforto ao executarem tais tarefas. Verificou-se, também, que as atividades que necessitam de postura inadequada são mais frequentes aos operários da manutenção que aos operadores, e que os operários de manutenção eletromecânica se expõem 

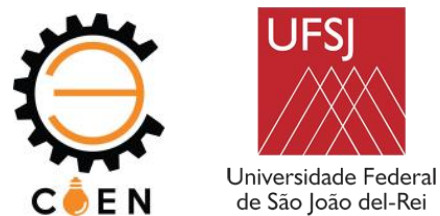

mais a posições danosas que os funcionários de eletroeletrônica. Contudo, não houve discriminação nas reclamações de dores e/ ou desconforto a respeito de atividades envolvendo posturas inadequadas, sendo comum a todos os cargos, o que não ocorreu com as atividades que exigem rígido controle de produção e/ ou ritmos excessivos, que apresentaram queixas apenas por parte dos trabalhadores dos setores de operação e manutenção eletromecânica.

$\mathrm{Na}$ avaliação por tempos de serviço prestado à empresa, foi observado que as atividades com maior exigência de esforço físico são direcionadas aos empregados com até 30 anos de casa. Entretanto, as queixas advindas dessas tarefas são dos funcionários com permanência inferior a 20 anos, sendo estes os que executam atividades que envolvem má postura. Todavia, os empregados que se encontram na faixa dos 20 a 30 anos trabalhados também sentem dores e/ ou desconfortos nesses tipos de atividades.

\section{CONCLUSÕES}

O presente artigo refere-se a uma pesquisa aplicada, fundamentada em revisão bibliográfica e em um estudo de caso, classificando-se como descritiva com abordagem qualitativa, visto que a empresa é a fonte direta para coleta de dados. Como na pesquisa descritiva não há interferência do pesquisador, o questionário apresentou-se como o método mais oportuno, visto que esta ferramenta permitiu acessar características subjetivas e algumas variáveis que afetam à percepção do trabalhador aos riscos da profissão.

O emprego de um referencial teórico previamente concebido auxiliou na apreciação comparativa dos dados coletados sendo, para efeito deste estudo, entrevistados 60 trabalhadores de uma empresa do setor de geração e transmissão de energia elétrica. Esse número se deu, primeiro, devido à necessidade de se ter a autorização do gerente pra enviar o questionário e porque a empresa impôs uma limitação à quantidade de emails enviados ao departamento para apenas dois, não sendo possível alterar tal resultado. Seu propósito foi analisar a percepção dos mesmos à exposição aos riscos inerentes à eletricidade, dos quais foram feitas inferências sobre a existência dos riscos ergonômicos e de acidentes a partir das variáveis idade, função desempenhada e tempo trabalhado na empresa. $\mathrm{O}$ indicador de gênero não foi considerado na análise, pois não influi sobre a noção de risco do trabalhador. Dessa forma, foram apresentados 15 questionamentos que se subdividiram em três tópicos, a saber: percepção aos riscos ergonômicos, autoavaliação dos danos derivados dos riscos ergonômicos e exposição aos riscos inerentes à eletricidade. Tais questionamentos geraram 15 respostas para cada uma das variáveis citadas, fornecendo um total de 2700 , em que posteriormente fez-se a interseção dos dados com os fatores em estudo, reduzindo para 45 o número de respostas a serem analisadas.

Assim, através dessa análise, pôde-se constatar que das 45 respostas geradas, apenas 13 apresentaram efeito estatístico significativo, ou seja, exibiram valor-p menor que 5\%, constatando que das atividades desempenhadas pelos funcionários da central elétrica, aquelas que exigem inadequação postural, esforço físico e controle rígido e/ ou ritmos excessivos de produção são percebidas e autoavaliadas como danosas pelos mesmos. Contudo, os autores observaram que a percepção desses riscos varia de acordo coma a idade, tempo de casa e cargo ocupado para cada grupo analisado.

Com base nos resultados obtidos, recomenda-se à empresa maior atenção perante aos riscos ergonômicos e adesão de programas que visem segurar o trabalhador em seu ambiente laboral como cursos e palestras focados no tema, por exemplo, buscando práticas inovadoras no mercado, bem como a modernização de seus equipamentos. Contudo, deve-se manter sua atual metodologia de treinamento em segurança quanto ao risco elétrico, em razão de sua eficiência.

A empresa já conta com o uso da ferramenta APR (Análise Preliminar de Risco), que pode ser feita por qualquer funcionário, por meio de uma plataforma na rede corporativa, que por sua vez, apresenta diversos riscos e medidas de controle pré-inseridas. Todavia, não foram encontrados riscos e medidas preventivas relacionadas ao risco ergonômico na mesma. Sendo assim, os autores sugerem a introdução dos agentes causadores de riscos ergonômicos e suas respectivas medidas preventivas na plataforma de 

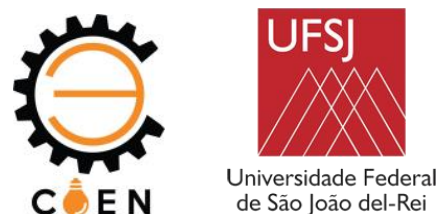

elaboração de APR, a fim de ampliar a percepção dos empregados quanto às periculosidades encontradas nesse meio laboral, conferindo-lhes mais segurança, diminuindo assim os danos causados à saúde do trabalhador.

\section{DIREITOS AUTORAIS}

Os autores são os únicos responsáveis pelo conteúdo das informações contidas neste artigo.

\section{REFERÊNCIAS}

ABNT. Gestão de Riscos - Princípios e diretrizes. NBR ISO 31000. Associação Brasileira de Normas Técnicas. 2009.

AREZES, Pedro Miguel Ferreira Martins. Percepção do Risco de Exposição Ocupacional ao Ruído. 2002. 269 f. Tese (Doutorado em Engenharia de Produção) - Escola de Engenharia da Universidade do Minho, Guimarães, Portugal.

BLOGOCOPACIONAL. A ergonomia no trabalho e seus benefícios para a saúde e o bem-estar dos trabalhadores. Disponível em: < http://www.ocupacional.com.br/ocupacional/aergonomia-no-trabalho-e-osseus-beneficios-para-a-saude-e-o-bem-estar-dos-trabalhadores/>. Acesso em: 28 abr. 2017.

BORGES, Janice Rodrigues Placeres; FABBRO, Amaury Lélis Dal; JUNIOR, Antonio Luiz Rodriguez. Percepção de riscos socioambientais no uso de agrotóxicos: o caso dos assentados da reforma agrária paulista. In: ENCONTRO NACIONAL DE ESTUDOS POPULACIONAIS, 14., 2004, Caxambú - MG.

BRASIL. Agência Nacional de Energia Elétrica. Atlas de Energia Elétrica do Brasil. Brasília, 2002. 199 p. Disponível em:<http://www2.aneel.gov.br/arquivos/pdf/livro_atlas.pdf>. Acesso em: 01 jul. 2017.

BRASIL. Ministério do Trabalho e Emprego. Normas Regulamentadoras de Segurança e Saúde no Trabalho. NR 10 - Segurança em instalações e serviços em eletricidade.

BRASIL. Ministério do Trabalho e Emprego. Normas Regulamentadoras de Segurança e Saúde no Trabalho. NR 17 Ergonomia.

CULCHESK, Aline Silva et al. Análise ergonômica do trabalho em uma serraria. In: ENCONTRO NACIONAL DE ENGENHARIA DE PRODUÇÃO, 2015, Fortaleza. http://www.abepro.org.br/biblioteca/TN_STP_209_240_27025.pdf>. Acesso: 03 jun. 2017.

Escola Nacional de Ciências Estatísticas. O que é Estatística. Disponível em: Acesso em: 08 jul. 2017.

FISCHER, Daniela; GUIMARÃES, Lia Buarque de Macedo; SCHAEFFER, Cíntia. Percepção de risco e perigo: um estudo qualitativo no setor de energia elétrica. In: ENCONTRO NACIONAL DE ENGENHARIA DE PRODUÇÃO, 22., 2002, Curitiba. Anais eletrônicos. 2002.

GUIMARÃES, Lia Buarque de Macedo. Análise macroergonômica do trabalho (AMT): modelo de implementação e avaliação de um programa de ergonomia da empresa. 2002. Artigo não publicado.

IIDA, Itiro. Ergonomia: projeto e produção. São Paulo: Edgard Blücher, 2005.

JUNIOR, Béda Barkokébas et al. Procedimentos de segurança para instalações elétricas em canteiros de obras. In: ENCONTRO NACIONAL DE ENGENHARIA DE PRODUÇÃO, 27., 2007, Foz do Iguaçu.

KMITA, Silvério Fonseca; GUIMARÃES, Lia Buarque de Macedo. Análise da satisfação dos funcionários com as melhorias ergonômicas implantadas na divisão de usinagem da John Deere Brasil.

MATHIAS, Sergio Larruscaim; SAKAI, Celio. Utilização da Ferramenta Google Forms no Processo de Avaliação Institucional: Estudo de Caso nas Faculdades Magsul. Disponível em:< http://download.inep.gov.br/educacao_superior/avaliacao_institucional/seminarios_regionais/trabalhos_regia o/2013/ce>. Acesso em: 09 jul. 2017.

OLIVEIRA, Maristela; VEIGA, Cristiano H. A.. Segurança e saúde no trabalho em cooperativa de distribuição de energia elétrica: percepções dos colaboradores. Ação Ergonômica. Volume 8, N², 2013. 

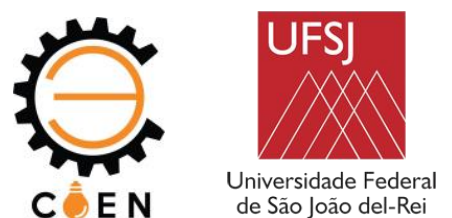

Organização Internacional do Trabalho - OIT. Doenças profissionais são principais causas de mortes no trabalho. Disponível em: < http://www.oitbrasil.org.br/content/doencas-profissionais-sao-principais-causasde-mortes-no-trabalho>. Acesso em: 02 jul. 2017.

SILVA, Alessandro José Nunes da. Análise organizacional de acidentes de trabalho no setor de distribuição de energia elétrica. 2015. 209 f. Tese (Mestrado em Saúde Coletiva) - Universidade Estadual Paulista "Júlio de Mesquita Filho" Faculdade de Medicina, Botucatu, São Paulo.

SILVA, Bernardete Ferreira da; FRANÇA, Sergio Luiz Braga. Análise da percepção do trabalhador sobre os riscos no ambiente de trabalho: estudo de caso em unidade de operação de empresa de energia brasileira. In: CONGRESSO NACIONAL DE EXCELÊNCIA EM GESTÃO, 7., 2011, Rio de Janeiro.

SILVA, Juliana Fernandes da Costa. Estresse Ocupacional e Suas Principais Causas e Consequências. 2010. 44 f. Tese (Especialização em Gestão Empresarial) - Universidade Cândido Mendes, da unidade centro II, Rio de Janeiro.

SOUTO, Clodovaldo Nogueira; ALBUQUERQUE, Gerson Luiz Apoliano. Percepção de risco: uma abordagem inovadora e participativa no setor elétrico. In: CONGRESSO TÉCNICO CIENTÍFICO DA ENGENHARIA E DA AGRONOMIA - SEMANA OFICIAL DE ENGENHARIA E DA AGRONOMIA, 72., 2015, Fortaleza.

VIEIRA, Kelmara Mendes; DALMORO, Marlon. Dilemas na Construção de Escalas Tipo Likert: o Número de Itens e a Disposição Influenciam nos Resultados?. In: ENCONTRO DA ANPAD, 32., 2008, Rio de Janeiro.

\section{ANALYSIS OF PERCEPTION TO EXPOSURE TO RISKS: A QUALITATIVE STUDY IN A COMPANY IN THE SECTOR OF ELECTRICITY GENERATION AND TRANSMISSION}

ABSTRACT: The article is an analysis of the perception of the risks, both ergonomic and accident, involving electricity to which a worker of a state-owned company of the electric power generation and transmission sector is exposed, whose aim is to attest the capacity of the same in perceive such risks, understanding their importance for safety and health at work. To this end, factors such as age, company time and function performed were collected, evaluating how these attributes affect the perception in each case, obtained from the application of semi-structured questionnaires in which the employee indicates the degree of agreement with affirmations regarding the aforementioned risks, on a predefined scale. Open questions were also applied, allowing a broader and more accurate analysis of individual perceptions of such risks, as well as the sense of security experienced by each employee. Due to the need to prove the data and to ensure scientific support for the conclusions, the statistical analysis of variance (ANOVA) was used, reaching results that indicate intense discrepancies in the average perception of the risks involved when comparing the different functions within the power plant, being smoother when compared to age or company time. From these results, conclusions were generated about the measures to be taken by the company's management.

KEYWORDS: Perception of risks, ergonomic risks, accident risks, electricity. 